\title{
Adopt-a-Hospital Project: An instructional tool for hospital administration
}

\author{
Asa B. Wilson* \\ Health Administration Division, Central Michigan University, United States
}

Received: July 27, 2016

Accepted: September 11, 2016

Online Published: September 23, 2016

DOI: $10.5430 /$ jha.v5n6p63

URL: http://dx.doi.org/10.5430/jha.v5n6p63

\begin{abstract}
Backgournd: More often than not, university health administration curriculums are generic and are not foundational to a specific career track. This is especially true in relation to the transition from graduation to a hospital administration career progression. The overarching question is, "How does one prepare themselves for senior leadership in an acute care hospital setting?"

Objective: A semester-long assignment - Adopt-a-Hospital Project - is discussed in the context of a healthcare finance course as tool for preparing students to think administratively regarding hospital operations. This Project is presented as an academic foundation preparing students for the required semester-long internship placement in an acute care hospital.

Results: The Project-Internship sequence has, over a four-year period, demonstrated its value as an academic and experiential learning bridge from the academy to the world of work. Informal, qualitative findings are discussed in terms of a future quantitative study incorporating: (1) preceptor surveys, (2) intern surveys, and (3) focus group feedback.

Conclusions: The Project-Internship sequence fosters a link between academic content and experiential learning in an acute care hospital - thereby augmenting one's post-graduation readiness to pursue a hospital administration career track.
\end{abstract}

Key Words: Health administration education, Hospital administration, Hospital financial management

\section{INTRODUCTION}

Health administration offerings within U.S. universities are largely generalist in nature unless efforts are made to prepare students for specific career tracks within health services. A recent study ${ }^{[1]}$ identified essential knowledge, skills, and attributes needed for success along the healthcare finance management track. However, there is limited evidence that the academy incorporates such findings into health administration curriculum design. In ways, there is limited continuity between the graduation-day walk and transition to a defined career progression. This reality is becoming a compelling challenge for universities as degree costs increase, student debt mounts, and job markets weaken. The resultant and intensifying expectation is that degree programs demonstrate a link between academic content, job readiness, and gainful employment.

This is true for aspiring hospital administrators currently engaged in degree programs - either at the bachelor or master's level. This reality is also a challenge for the academy and its applied mission and career readiness obligation to its students. That is, with some exceptions, it is rare that health administration curriculums are aligned with post-graduation career tracks or lay a clear career readiness foundation. As such, health administration graduates must, over time, cobble together a portfolio of: (1) experience, (2) continuing education, (3) mentoring support, (4) competencies, and

\footnotetext{
* Correspondence: Asa B. Wilson, Asst. Prof.; Email: wilso1ab@cmich.edu; Address: Central Michigan University, 208 Rowe Hall, Mount Pleasant, MI 48859, United States.
}

Published by Sciedu Press 
(5) progressive career advancement in order to demonstrate readiness for senior level experience.

Such a situation creates decision-making challenges for individuals aspiring to hospital senior leadership positions. In addition, the emerging dynamic within U.S. hospitals is intensifying competitive advancement opportunities and demanding amended hospital business strategies. For example, consumerism requires movement of care closer to and more convenient for patients - all at lower cost. Managerialism is prompting significant investment in mergers and acquisitions (M\&A) for the creation of large inpatient-centric networks of care. It is argued that the momentum of consumer-centric outpatient centers and emerging virtual modalities of access are disrupting the historical status quo of hospitals. ${ }^{[2]}$ While these countervailing trends create strategic and operational distress for hospital executives, the academy is confronted with a readiness difficulty, e.g., "How can health administration programs facilitate student readiness for hospital leadership roles?"

\subsection{Purpose}

The purpose of this paper is to discuss the positive impact of a semester-long project focused ostensibly on the financial management of hospitals. The Adopt-a-Hospital Project provides a conceptual framework within which assignments require hands-on analysis of a hospital fiscal performance as evidenced in a publically available audit report. The project's charge to students is "to become as familiar with your adopted hospital's fiscal strengths and weaknesses - as if you worked there". An additional purpose is to highlight the emerging link between the project and student readiness for the curriculum's required semester-long internship.

\subsection{Background}

A financial management course, as its statistics course relative is a dreaded requirement that is delayed until it is absolutely unavoidable. Also, course content is presumed to be of limited interest to a majority of undergraduate students - a mindset bulwarked by prior experience with a financial or managerial accounting prerequisite. A frequent cry is, "I don't see why I need this course; I'm going into Human Resources!"

Such an outlook is: (1) a student engagement challenge, (2) a content delivery difficulty, and (3) a student satisfaction survey "mine field" for faculty. As a result, the course's instructional design and delivery elements are essential engagement success factors - for students and instructors. Thus, a key instructional concern is how to foster engagement and reduce opposition - in everyone's best interest and for longrun success.
In like manner, the U.S. health industry is confronted with financial challenges associated with reimbursement amendments, new organizational configurations, expanded government regulations, and external reporting requirements. These pressures are captured in the language associated with increased usage of the phrase, healthcare value. Specifically, implementing provisions of the Affordable Care Act (ACA) has intensified the role of an organization's fiscal function through alternative business models, an increased rate of $M \& A$, plus revised reimbursement formats.

These activities require a strategic and operating "marriage" between fiscal efficiency and quality effectiveness. The finance-quality linkage is emerging under the umbrella of healthcare value. ${ }^{[3]}$ Specifically, "The arc of history is increasingly clear: health care is shifting focus from the volume of services delivered to the value created for patients, with 'value' defined as outcomes achieved relative to the costs". ${ }^{[4]}$

\section{Adopt-a-Hospital Project}

The project is a semester-long series of eight assignments linked to and aligned with content typical of a healthcare financial management course. Even though the course is largely didactic, the project is an experiential learning exercise in which analytical content is applied to an acute care hospital's fiscal performance as well as its strategic positioning and community impact. ${ }^{[5]}$

The project's central purpose is to "adopt" an acute care hospital by using its annual audit report and other sources to gain familiarity with its vision, mission, operations, and fiscal status. This is a worthy challenge because one must rely upon objective fiscal results to conduct analyses, make interpretations, and recommend actions; accomplished in the absence of first-hand employee experience. The Adopt-aHospital Project applies course content it to an analysis of an actual hospital's financial statements secured from publically available annual audit reports. Such an applied approach establishes an understanding of financial reporting, analysis of outcomes, and interpretation of operational implications. Gaining new insight or strengthening existing fiscal skills will redound to: (1) course success, (2) internship performance, and (3) job-search readiness.

\subsection{Rationale for the project}

The course's recurrent theme - "Think Like and Administrator" - is embedded in each lecture, assignment, problem set, article analysis, and exam. As such, the theme is an on-going answer to the question, "Why are these course requirements of value to me?" with the answer being, "They encourage you to think like an administrator". Administrative critical thinking is an important cognitive posture directly associated 
with academic success and professional growth - no matter the level of one's position in a facility. Working through the Adopt-a-Hospital Project's eight assignments fosters an ability to use financial outcomes in support of strategic and operating decisions, i.e., thinking like an administrator! ${ }^{[6]}$

\subsection{Project description}

At the outset of the semester, students are assigned responsibility for one hospital with no students having the same hospital. The "adopted hospitals" represent acute care facilities for which a current annual audit report is publically available with no copy write restrictions. Since all of the adopted facilities are out of state, none of the students had first-hand experience with their hospital and no student interned in their adopted organization. The project is an adjunct experience focused on the application of course content to the fiscal performance of an actual acute care hospital. Students are encouraged to consider that the sequence of eight assignments enable them to be conversant with the fiscal strengths and weaknesses of their "adopted" facility - as if they worked in the hospital. An corollary purpose is to study the environments in which the respective organizations are embedded.

The Project was piloted with health administration undergraduates because they are the largest group of students. Since the required finance course is one of the last courses taken before the capstone, it was possible to assess the course impact on internship performance. The internship is available three times a year. The table below summarizes internship enrollment during the past four years. Students are placed in health facilities throughout the state depending upon professed interest and preceptor acceptance.

\subsection{Project outline}

Table 1 summarizes the eight assignments according to their purpose and required data source. Assignments 1 through 3 focus on capturing routine contact information, specifying the service area, and defining the organization. The premise is that the each hospital is embedded in a defined geography having equally defined characteristics. This information is a foundation that used to assess the extent to which hospital operations are aligned with area demographics and community needs.

Embedded in Assignment 3 is the task of deconstructing the facility's Vision and Mission statements. Figure 1 is a summary of the template used for this assignment element. The first step is to identify the core elements in each statement and list them in the template. The second step is to delineate activities that support fulfillment of each element of the deconstructed Vision and Mission statements. This exercise

Published by Sciedu Press drives strategic and operational thinking about activities that support attainment of core aspects of the facility's public statements about its identity and purpose. The end result is a sensitivity to the important relationship among financial management, strategic positioning of the hospital, and other aspects of hospital operations. This exposure also creates an appreciation for Porter's ${ }^{[3]}$ definition of healthcare quality in terms of value provided considering fiscal prudence and long-run patient outcomes.

Assignments 4 through 7 focus on ratio analysis of financial results shown in the audit report's financial statements. All of the required ratios indicative of Profitability, Liquidity, Asset Management, and Debt Management are to be calculated using only the financial statements and Notes to Financial Statements. Each assignment has the two-fold purpose of: (1) accurately calculating the required ratios, and (2) correctly interpreting the results according to internal trends and external industry benchmarks.

Assignment 8 is a summary exercise in which one: (1) provides a review of the ratio analysis, and (2) builds an informed narrative of the organizations fiscal strengths and weaknesses. In Assignment 8, the task is to consolidate ratio analysis results by developing a narrative justifying a view of the hospital's fiscal status. In addition, students are ask to: (1) identify recommended actions to address weaknesses, and (2) recommend actions to build on existing strengths. An additional requirement is to narrate a position regarding how well hospital performance is aligned with service area needs, including community benefit provisions. Doing so involves integrating information from Assignments 1, 2 and 3 with the fiscal results from Assignments 4 through 7. Students are asked to "Think like an Administrator" as they build a position statement on the mission effectiveness of their adopted facility.

\section{Discussion - Project Strengths AND CHALLENGES}

Over a four-year period of experience with the Project, a number of instructional strengths have been identified. In addition, opportunities for improvement have surfaced and are identified as follows:

\subsection{Strengths ended here}

A working assumption is that health administration is an applied academic discipline - one by which individuals are prepared to enter the workforce and/or pursue advanced degrees. Further, an applied program obligates the academy to ensure that curriculum content fosters cognitive strengths and applied skills in readiness for transitioning into the workplace. 
Table 1. Adopt-a-Hospital Project assignments

\begin{tabular}{|c|c|c|c|}
\hline Number & Assignment & Purpose & Data Sources ${ }^{*}$ \\
\hline 1. & $\begin{array}{l}\text { Routine Facility } \\
\text { Information }\end{array}$ & $\begin{array}{l}\text { Create a table of hospital location and contact information. } \\
\text { (Rubric provided) }\end{array}$ & $\begin{array}{l}\text { - Hospital Web Page } \\
\text { - AHA Hospital Guide }\end{array}$ \\
\hline 2. & Service Area Description & $\begin{array}{l}\text { Capture demographic, location, population, geographic, } \\
\text { income, insurance, business, and health service needs } \\
\text { characteristics to compile a description of the facility’s } \\
\text { service area. (Rubric provided) }\end{array}$ & $\begin{array}{l}\text { - AHA Hospital Guide } \\
\text { - www.census.gov } \\
\text { - Community Health Needs } \\
\text { Assessment (CHNA) } \\
\text { - County/City Web Pages }\end{array}$ \\
\hline 3. & Facility Description & $\begin{array}{l}\text { Gather scope of care, physician mix, bed size, community } \\
\text { benefit provisions, control status, Board and Administrative } \\
\text { makeup, physical plant detail, awards received, foundation } \\
\text { structure, specialty services, and relevant affiliations. } \\
\text { Compile information into a detailed facility description. } \\
\text { (Rubric provided) }\end{array}$ & $\begin{array}{l}\text { - AHA Hospital Guide } \\
\text { - Annual Audit Report } \\
\text { - Notes to Financials } \\
\text { - Community Benefit Report } \\
\text { - IRS Form } 990 \\
\text { - Medicare Cost Report }\end{array}$ \\
\hline 4. & $\begin{array}{l}\text { Ratio Analysis: } \\
\text { Profitability Outcome }\end{array}$ & $\begin{array}{l}\text { - Articulate a definition of Profitability } \\
\text { - Calculate four profitability ratios } \\
\text { - Narrate conclusions about one's hospital }\end{array}$ & $\begin{array}{l}\text { - Annual Audit Report } \\
\text { - Notes to Financial Statements }\end{array}$ \\
\hline 5. & $\begin{array}{l}\text { Ratio Analysis: Liquidity } \\
\text { Status }\end{array}$ & $\begin{array}{l}\text { - Articulate a definition of Liquidity } \\
\text { - Calculate three liquidity ratios } \\
\text { - Narrate conclusions about one’s hospital }\end{array}$ & $\begin{array}{l}\text { - Annual Audit Report } \\
\text { - Notes to Financial Statements }\end{array}$ \\
\hline 6. & $\begin{array}{l}\text { Ratio Analysis: Debt } \\
\text { Management }\end{array}$ & $\begin{array}{l}\text { - Build a definition of Debt Management } \\
\text { - Calculate four profitability ratios } \\
\text { - Narrate conclusions about one's hospital }\end{array}$ & $\begin{array}{l}\text { - Annual Audit Report } \\
\text { - Notes to Financial Statements }\end{array}$ \\
\hline 7. & $\begin{array}{l}\text { Ratio Analysis: Asset } \\
\text { Management }\end{array}$ & $\begin{array}{l}\text { - Build a definition of Asset Management } \\
\text { - Calculate four profitability ratios } \\
\text { - Narrate conclusions about one's hospital }\end{array}$ & $\begin{array}{l}\text { - Annual Audit Report } \\
\text { - Notes to Financial Statements }\end{array}$ \\
\hline 8. & $\begin{array}{l}\text { Strengths and Weakness } \\
\text { Summary }\end{array}$ & $\begin{array}{l}\text { - Narrate fiscal strengths and opportunities with community } \\
\text { alignment argument }\end{array}$ & $\begin{array}{l}\text { - Annual Audit Report } \\
\text { - All Prior Assignments }\end{array}$ \\
\hline
\end{tabular}

* Project directions request that the most current sources are used for research, calculations, and narratives

\subsubsection{Undergraduate internship fit and job readiness}

A major problem with an internship curriculum requirement for both students and site preceptors is ensuring a match between student interest and site opportunities. Preceptors want assurance that they can meet student interests and support academic requirements. Internship Coordinators must "push" students to clarify their internship goals in order to facilitate a best fit. Post-internship focus groups confirm the value of this match. In addition, students report that Project assignments enabled them to perform well as interns. This outcome was especially true for those placed in acute care hospitals and who subsequently pursued hospital employment. Focus group feedback indicated that the Project-Internship sequence instilled confidence in acquired skills, relevance of health service knowledge, job-search direction, and career commitment.

\subsubsection{Rigor flexibility across degree levels}

The Adopt-a-Hospital Project has also been successfully incorporated in to BA, MHA, and DHA curriculum finance offerings; flexibility that has been accomplished by adjusting or aligning the rigor of each Project assignment with respective degree levels.

\subsubsection{Decision support analysis}

An essential feature of thinking like and administrator is the pursuit of lifelong information literacy and building wellequipped methodological tool box. ${ }^{[6]}$ The Project's assignments provide direct exposure to analyzing operating results and demonstrate how analysis is a decision-making prerequisite. That is, analysis is shown not to be and end point. Rather, it offers information that prompts and guides administrative action. For example, a negative total margin and negative operating margin should signal the need for internal operating adjustments to enhance profitability. Equally so, such results argue that the facility is not meeting its professed mission in relation to the community, i.e., in today's health service environment financial outcomes are indicative of far more than debit-and-credit reporting.

\subsection{Shortcomings}

There are some shortfalls associated with this project, yet they provide opportunities to encourage students regarding readiness gains to be realized from this experiential learning exercises. Those issues and opportunities as outlined as follows: 
Vision Statement

\begin{tabular}{|l|l|}
\hline Vision Statement & “We will be the regional leader in healthcare” \\
\hline Core Elements & Strategic/Operating/Financial Implications \\
\hline Regional Leader & \\
\hline Health Services & \\
\hline
\end{tabular}

Mission Statement

\begin{tabular}{|l|l|}
\hline Mission Statement & $\begin{array}{l}\text { “Community Hospital is committed to improving the } \\
\text { health of the people in our communities by providing } \\
\text { excellent care and working with local agencies to meet } \\
\text { community health needs” }\end{array}$ \\
\hline Core Elements & Strategic/Operating/Financial Implications \\
\hline Improving Population Health Status & \\
\hline Providing Excellent Care & \\
\hline Meeting CHNA Findings & \\
\hline
\end{tabular}

Figure 1. Vision and mission statements deconstructing template

\subsubsection{Student opposition}

At the outset, there is generalized student objection to the presumed volume of Project assignments and the overall rigor of the semester-long exercise. Also, a tendency exists to object to the fact that no students have "adopted" the same hospital, i.e., each person is directly responsible for researching and analyzing the details of their unique hospital. The instructional challenge is to persist with encouragement regarding the Project's long-run value using class time to review assignments, demonstrate access to data sources, and provide interpretive guidance on calculated results. The provision of well-designed assignment templates and rubrics eases student challenges. Yet, as the course progresses, students frequently volunteer insights, e.g., "These numbers really speak to me about my hospital." This insight is often followed with an understanding of an administrator's exercise of management control to guide operations toward desired outcomes.

\subsubsection{Instructional demands}

Eight Project assignments, each based on a different hospital audit report for each student, create a time-intensive grading challenge. Grading requires a review of data sources and financial statements for each student's hospital for each assignment. An alternative approach would be to assign one facility to a small group of students who are collectively responsible for preparing one version of each of the eight assignments. However, doing so dilutes the simulated standalone hospital executive responsibility for capturing, analyzing, and interpreting facility operating results. This learning outcome is considered more important than the associated grading time requirements.

\subsubsection{Access to operating indicators}

Finding current hospital audit reports is not problematic, yet securing access to annual operating indicators can be difficult. If the Notes to Financial Statements do not summarize key indicators, the difficulty persists. Operating details are not provided uniformly on facility web pages or in audit reports. Also, Schedules S1 through S4 of the Medicare Cost Report provide limited operating statistics. Accessing this information from the Medicare Healthcare Cost Report Information System (HCRIS) data base can be a concern for students with limited experience using MS Access queries for imported data.

However, Schedule D of the AHA Annual Survey Database ${ }^{[7]}$ provides limited indicators in the categories of: (1) Beds and Utilization, (2) Medicare/Medicaid Utilization, and (3) Fi- 
nancial. The difficulty with the Annual Database is it annual cost. Yet, if the annual four-figure cost issue can be resolved, the Database has the needed operating indicator and scope of service detail that can be retrieved for each student.

\subsubsection{Study limitations}

The argument is a qualitative overview of a specific course project that has pragmatic internship- and job-readiness value. As such, the presentation suffers the weaknesses of a quantitative assessment of: (1) student ratings, (2) follow-up focus group themes, and (3) internship preceptor ratings. These short falls identify opportunities for a quantitative study that incorporates these details into the current qualitative scaffolding.

\section{Conclusions}

The Adopt-a-Hospital Project has qualitatively shown to be an experiential learning exercise - one that encourages students to "Think like an Administrator" and to profit from placement in a hospital internship. In addition, follow-up tracking of students shows a 50 percent hiring rate by the internship site facility. The structure of the Project's assignments underscores the intensifying relationship between financial management, performance improvement, quality outcomes, regulatory compliance, e.g., essential administrative responsibilities.

An instructional and experiential learning opportunity is provided that conveys the message that hospital administration is a matter of successfully orchestrating interaction among all facility functions. The ability to lay such a foundation via this project encourages students to align their health administration career interests with internship opportunities and thereby maximizing their post-graduation hospital job-search readiness. These attributes are best established or begun in the academy before one walks across the graduation stage into the world of work!

\section{CONFlicts OF INTEREST Disclosure}

The authors declare they have no conflicts of interest.

\section{REFERENCES}

[1] Rochester C, Berkshire SD, Wilson AB, et al. CFO development and success in the era of healthcare reform, Healthcare Financ Mgt. 2015 August: 1-4.

[2] Kaufman K, Grube ME. Succeeding in a disruptive healthcare environment. Healthcare Financ Mgt. 2015; 49-55.

[3] Porter ME. What is value in health care? New England Journal of Medicine. 2010; 363(26): 2477-2481. PMid: 21142528. http://dx.doi.org/10.1056/NEJMp1011024

[4] Porter ME, Larsson S, Lee TH. Standardizing patient outcomes measurement. New England Journal of Medicine. 2016; 376(6): 504-506.
PMid: 26863351. http://dx.doi.org/10.1056/NEJMp151170 1

[5] Kolb D. Experiential Learning: Experience As the Source of Learning and Development. Pearson Schweiz Ag. 1984; 1(3): 16-17.

[6] Wilson AB. Think like an administrator: A course design and delivery template for health administration. J Health Admin Ed. 2016; 32: 22-34.

[7] AHA Annual Survey Database. American Hospitals Association. 2014. 